\title{
ENCOURAGING PERFORMANCE BEHAVIOR BHINNEKA FOUNDATION TEACHER BOYOLALI WORKS
}

\author{
Unna Ria Safitri \\ Fakultas Ekonomi Universitas Boyolali \\ unnaria68@gmail.com
}

\begin{abstract}
ABSTRAK
Suatu organisasi yang besar, maka akan menimbulkan masalah yang beragam dihadapi oleh organisasi, terutama bidang manajemen. Kepemimpinan memegang peranan yang penting dalam peningkatan kinerja karyawan. Tanpa adanya kepemimpinan dan bimbingan maka suatu organisasi tidak bisa tercapai sesuai dengan tujuannya. Yayasan Bhinneka Karya Boyolali muncul masalah diantaranya adalah kinerja Guru yang menurun disebabkan oleh kurang tersedianya sarana dan prasarana yang mendukung kinerja guru, faktor kepemimpinan juga mempengaruhi kinerja guru, karena keberhasilan suatu organisasi sangat tergantung pada kualitas kepemimpinan yang mampu memotivasi, mengarahkan, mempengaruhi dan berkomunikasi dengan bawahannya supaya tujuan organisasi itu bisa tercapai secara optimal. Penelitian ini bertujuan untuk menganalisis Pengaruh Kepemimpinan Dan Lingkungan Kerja Terhadap Karyawan Melalui Kepuasan Kerja (Studi Kasus Pada Guru Yayasan Bhinneka Karya Boyolali). Penelitian ini menggunakan metode analisis uji instrumen yang meliputi uji validitas dan uji realibilitas, uji liniaritas, analisis regresi, analisis jalur yaitu pengaruh langsung, pengaruh tidak langsung dan pengaruh total. Uji t, Uji F, Uji koefisien determinasi dan analisis korelasi. Dari hasil kuisioner yang didapat Hasil Uji Hipotesa adalah : Kepemimpinan berpengaruh signifikan terhadap kepuasan kerja.Lingkungan kerja berpengaruh signifikan terhadap kepuasan kerja karyawan. Kepemimpinan berpengaruh signifikan terhadap kinerja, lingkungan kerja berpengaruh signifikan terhadap kinerja karyawan. Hasil uji $\mathrm{F}$ diketahui besarnya nilai $F=101,998$ sig $0,000<0,05$. Sehingga dapat disimpulkan secara bersama-sama kepemimpinan, lingkungan kerja dan kepuasan kerja berpengaruh signifikan terhadap kinerja karyawan Pada Guru Yayasan Bhinneka Karya Boyolali. Nilai $\mathrm{R}^{2}$ total sebesar 0,970 artinya variasi kinerja karyawan pada guru yayasan bhinneka karya boyolali dijelaskan oleh variabel kepemimpinan, lingkungan kerja dan kepuasan kerja sebesar 97,0\% dan sisanya 3,0\% dijelaskan variabel lain diluar model penelitian. Diketahui hasil analisa jalur lingkungan kerja terhadap kinerja merupakan jalur efektif untuk meningkatkan kinerja.
\end{abstract}

Kata Kunci : Kepemimpinan, lingkungan kerja, kepuasan kerja, kinerja karyawan

\section{ABSTRACT}

A large organization, it will cause various problems faced by organizations, especially in the field of management. Leadership plays an important role in improving employee performance. Without leadership and guidance, an organization cannot be achieved according to its objectives. Bhinneka Karya Boyolali Foundation arises a problem, among them is the decreasing performance of the teacher due to lack of availability of facilities and infrastructure that support teacher performance, leadership factors also affect teacher performance, because the success of an organization depends on leadership quality that is able to motivate, direct, influence and communicate with subordinates so that the goals of the organization can be achieved optimally. This study aims to analyze the Effect of Leadership and Work Environment on Employees Through Job Satisfaction (Case Study on Teachers of Bhinneka Karya Boyolali Foundation). This study uses the instrument test analysis method which includes validity and reliability test, linearity test, regression analysis, path analysis, namely direct influence, indirect influence and total influence. $T$ test, $F$ test, test the coefficient of determination and correlation analysis. From the results of the questionnaire obtained Hypothesis Test Results are: Leadership has a significant effect on job satisfaction. The work environment has a significant effect on employee job satisfaction. Leadership has a significant effect on performance, the work environment has a significant effect on employee performance. $F$ test results are known to be the value of $F=101.998$ sig $0.000<0.05$. So that it can be concluded together leadership, work environment and job satisfaction have a significant effect on the performance of employees at the Bhinneka Karya Boyolali Foundation Teachers. The total $\mathrm{R}^{2}$ value of 0.970 means that the variation of employee performance in the teachers of various foundation boyolali works is explained by the variables of leadership, work environment and job satisfaction by $97.0 \%$ and the remaining $3.0 \%$ are explained by other variables outside the research model. It is known that the results of the analysis of the work environment path to performance is an effective pathway to improve performance.

Keywords: Leadership, work environment, job satisfaction, employee performance 


\section{PENDAHULUAN}

Suatu organisasi yang besar, maka akan menimbulkan masalah yang beragam dihadapi oleh organisasi, terutama bidang manajemen. Beragamnya masalah yang dihadapi maka tergantung dengan manajemen yang mengakibatkan meningkatnya kebutuhan pimpinan yang memiliki kualitas tinggi, yang dapat mengarahkan karyawan untuk meningkatkan kinerja dalam pencapaian tujuan organisasi sesuai dengan visi,misi organisasi. Kepemimpinan memegang peranan yang penting dalam peningkatan kinerja karyawan. Tanpa adanya kepemimpinan dan bimbingan maka suatu organisasi tidak bisa tercapai sesuai dengan tujuannya. Kondisi tersebut akan akan menimbulkan situasi individu saat bekerja untuk mencapai tujuan pribadinya, sementara organisasi menjadi tidak efisien dalam pencappaian yang sudah direncanakan sebelumnya.

Dari masalah diatas maka Yayasan Bhinneka Karya Boyolali muncul masalah diantaranya adalah kinerja Guru yang menurun disebabkan oleh kurang tersedianya sarana dan prasarana yang mendukung kinerja guru, faktor kepemimpinan juga mempengaruhi kinerja guru, karena keberhasilan suatu organisasi sangat tergantung pada kualitas kepemimpinan yang mampu memotivasi, mengarahkan, mempengaruhi dan berkomunikasi dengan bawahannya supaya tujuan organisasi itu bisa tercapai secara optimal.

Siagian (2008: 2) menyatakan bahwa "keberhasilan suatu organisasi baik sebagai keseluruhan maupun berbagai kelompok dalam suatu organisasi tertentu, sangat tergantung pada mutu kepemimpinan yang terdapat dalam organisasi itu sendiri”. Pendapat ini mencerminkan betapa besar peran kepemimpinan yang terdapat dalam organisasi, sehingga pemimpin diharapkan mempunyai kemampuan untuk memotivasi, mengarahkan, mempengaruhi dan berkomunikasi dengan bawahannya supaya tujuan organisasi itu bisa tercapai secara efektif dan efisien.

Pengembangan karyawan di dalam era teknologi memegang peranan penting dalam suatu organisasi dalam mengimplementasikan di dunia nyata karena sumber daya manusia selalu berperan aktif dan dominan dalam setiap kegiatan organisasi, manusia menjadi perencana, pelaksana, serta penentu terwujudnya tujuan organisasi. Tindakan-tindakan manajemen tersebut satu sama lain saling berkaitan dan merupakan tugas setiap pemimpin untuk mengatur sumber daya yang ada dalam melaksanakan berbagai pekerjaan dalam pencapaiuan tujuan organisasi.

Menurut Ambar Teguh Sulistiyani (2003 : 223)"Kinerja seseorang merupakan kombinasi dari kemampuan, usaha dan kesempatan yang dapat dinilai dari hasil kerjanya". Maluyu S.P. Hasibuan (2001:34) mengemukakan "kinerja (prestasi kerja) adalah suatu hasil kerja yang dicapai seseorang dalam melaksanakan tugas tugas yang dibebankan kepadanya yang didasarkan atas kecakapan, pengalaman dan kesungguhan serta waktu"

Menurut T. Hani Handoko (Handoko, 1995:135) "Penilaian prestasi adalah proses melalui mana organisasi-organisasi mengevaluasi atau menilai prestasi kerja karyawan. Dimana kegiatan ini dapat memperbaiki keputusankeputusan personalia dan memberikan umpan balik kepada karyawan tentang pelaksanaak kerja mereka." Penilaian prestasi kerja adalah proses yang digunakan pimpinana Yayasan Bhinneka Karya Boyolali untuk menentukan apakah seorang guru malakukan pekerjaannya sesuai dengan tugas dan tanggung jawab. Dalam mencapai visi, misi dan tujuan organisasi perlu meningkatkan kinerja karyawan agar dapat mencapai kualitas kerja yang optimal.

Sistematis untuk mengetahui hasil pekerjaan karyawan dan kinerja organisasi merupakan penilaian yang harus dilakukan. Menentukan kebutuhan pelatihan kerja secara tepat, memberikan tanggung jawab yang sesuai kepada karyawan sehingga dapat melaksanakan pekerjaan yang lebih baik di masa mendatang dan sebagai dasar untuk menentukan kebijakan dalam hal promosi jabatan. Berdasarkan hal tersebut, kinerja sangat penting untuk ditingkatkan dilingkungan Yayasan Bhinneka Karya Boyolali.

Menurut Veizal Rivai ( 2004: 309) mengemukakan kinerja adalah :“ merupakan perilaku yang nyata yang ditampilkan setiap orang sebagai prestasi kerja yang dihasilkan karyawan sesuai dengan perannya dalam perusahaan". Sedangkan menurut Robert L. Mathis dan John H. Jackson Terjamahaan Jimmy Sadeli dan Bayu Prawira (2001: 78), "menyatakan bahwa kinerja pada dasarnya adalah apa yang dilakukan atau tidak dilakukan karyawan". Berdasarkan uraian para ahli diatas maka penelitian ini akan dikaji kinerja guru Yayasan Bhinneka Karya Boyolali.

Seorang karyawan yang tidak memperoleh kepuasan kerja maka karyawan akan bermalasmalasan dalam bekerja. Tidak memiliki semangat kerja, sering absen dan melakukan kesibukan yang tidak ada hubungannya dengan 
pekerjaan yang harus dilakukan. Oleh karena itu kepuasan kerja mempunyai arti penting baik bagi karyawan maupun organisasi. Menurut Barley et al., (2000:24) menyatakan kepuasan kerja adalah suatu tingkat dimana seseorang merasa positif atau negatif tentang berbagai segi dari pekerjaan, tempat kerja dan hubungannya dengan teman kerja. Dalalm era teknologi implementasi di dunia nyata sangat penting dan besar pengaruhnya, karena sumber daya manusia berperan aktif dalam organisasi, terwujudnya tujuan organisasi tergantung dari manusia itu sendiri.Tugas pemimpin yaitu mengatur mengatur sumber daya yang ada dan melaksanakan sesuai tujuan organisasi. Seorang pemimmpin sangat mempengaruhi keberhasilannya.

Hasil penelitian Rahmila Sari (2011) hsil penelitiannya menyatakan bahwa, kepuasan berpengaruh signifikan terhadap kinerja. Stephani Ranto Kurniawan, Faustine (2014) hasil penelitian yang relevan bahwa kepuasan berpengaruh tidak signifikan terhadap kinerja.

Kesenjangan antara fenomena, teori dan temuan penelitian terdahulu ini menimbulkan gap teori maupun gap penelitian sehingga berpeluang untuk dikaji lebih mendalam hubungan antara variabel tersebut yaitu pengaruh anatra kepuasan kerja terhadap kinerja guru Yayasan Bhinneka Karya Boyolali.

Norma perilaku yang digunakan oleh seseorang pada saat orang tersebut mencoba mempengaruhi perilaku orang lain adalah norma kepemimpinan. Komunikasi antara pemimpin dan bisa diterima bawahannya merupakan tujuan dari organisasi. Pemimpin harus menerapkan gaya kepemimpinannya untuk mengelola bawahannya, karena seorang pemimpin akan sangat mempengaruhi keberhasilan organisasi dalam mencapai tujuannya. Seorang pemimpin yang baik harus bisa mendengarkan ide-ide dari bawahannya sebelum mengambil keputusan, agar terhindar dari kesalahan dan bawahan puas.

Kinerja merupakan faktor yang mempengaruhi lingkungan kerja. Lingkungan kerja adalah tempat karyawan melakukan aktivitas pekerjaan setiap harinya. Lingkungan kerja kondusif akan memberi rasa aman dan dan nyaman sehingga dapat bekerja secara optimal. Lingkungan kerja dapat mempengaruhi emosional karyawan. Jika karyawan merasa senang lingkungan kerja di mana dia bekerja, maka karyawan tersebut akan betah di tempat kerjanya. Sehingga produktivitas akan tinggi dan otomatis prestasi kerja karyawan juga tinggi. Lingkungan kerja itu mencakup hubungan kerja antara bawahan dan atasan serta lingkungan fisik tempat karyawan bekerja.

Begitu pentingnya lingkungan kerja bagi karyawan Yayasan Bhinneka Karya Boyolali adalah untuk memberikan semangat kerja, dengan fasilitas-fasilitas kerja yang memadai. Lingkungan kerja bisa penyebab dari keberhasilan dalam melaksanakan suatu pekerjaan. Tetapi juga bisa menyebabkan kegagalan dalam suatu pekerjaan. Ruang kerja akan dapat mempengaruhi pekerja, apabila seorang pekerja mendapat pengaruh yang positif, maka pekerja tersebut akan mempunyai moral yang lebih baik dalam melakukan pekerjaannya, dan ini berarti akan meningkat efisiensi dalam pencapaian suatu tujuan

Berdasarkan uraian di atas, bahwa dengan kepemimpinan yang sesuai dengan kondisi karyawan di tempat kerja, lingkungan kerja yang mendukung, budaya organisasi yang baik dan kepuasan kerja yang cukup dapat meningkatkan kinerja karyawan, maka penulis terdorong untuk melakukan penelitian dengan mengambil judul "Pengaruh Kepemimpinan Dan Lingkungan Kerja Terhadap Kinerja Karyawan Melalui Kepuasan Kerja (Studi Kasus Pada Guru Yayasan Bhinneka Karya Boyolali)".

\section{METODE}

Desain yang digunakan dalam penelitian ini adalah Desain Korelasional. Penerapan dalam penelitian ini adalah mengkorelasikan variabel bebas yaitu kepemimpinan $\left(\mathrm{X}_{1}\right)$, lingkungan kerja $\left(\mathrm{X}_{2}\right)$, dan variabel intervening kepuasan kerja $\left(\mathrm{X}_{3}\right)$, dengan variabel terikat yaitu kinerja $(\mathrm{Y})$, serta untuk menguji hipotesis-hipotesis yang telah dirumuskan. Seluruh data yang diperoleh akan diproses dan diolah dengan suatu analisa kuantitatif.

Tujuan penelitian ini adalah untuk mengetahui dan menganalisis secara empirik pengaruh kepemimpinan dan lingkungan kerja terhadap kinerja melalui kepuasan kerja karyawan pada Guru Yayasan Bhinneka Karya Boyolali. Dengan teknik penelitian sensus dengan mengambil sampel sebanyak 100 responden.

Lokasi dalam penelitian ini adalah seluruh Guru Yayasan Bhinneka Karya Boyolali dengan alamat kantor Yayasan Bhinneka Karya Jl Pandanaran 405 Boyolali. Obyek dalam penelitian ini adalah seluruh karyawan pada Guru Yayasan Bhinneka Karya Boyolali. Untuk memperoleh gambaran mengenai obyek penelitian, peneliti menggunakan kuesioner.

Populasi adalah keseluruhan subjek penelitian. Penelitian populasi dilakukan apabila 
seseorang ingin meneliti semua elemen yang ada dalam wilayah penelitian. Studi atau penelitiannya juga disebut studi populasi atau studi sensus (Arikunto, 2007:109). Populasi dalam penelitian ini adalah seluruh karyawan pada Guru Yayasan Bhinneka Karya Boyolali yang terdiri dari 100 guru.

Sampel adalah sebagian dari jumlah dan karakteristik yang dimiliki oleh populasi (Sugiyono, 2007:151). Metode sampel yang digunakan oleh peneliti adalah sensus yaitu jumlah populasi seluruhnya dijadikan sampel dengan pertimbangan karena peneliti mampu memperoleh data dari seluruh responden yang ada, sehingga jumlah sampel dalam penelitian ini berjumlah 100 responden.

Dalam penelitian ini sebagai data primer, yaitu data yang diperoleh langsung dari karyawan pada Guru Yayasan Bhinneka Karya Boyolali, yaitu tentang kepemimpinan, lingkungan kerja, kepuasan kerja dan kinerja. Teknik Pengumpulan Data

Dalam penelitian ini peneliti mengamati kondisi masing-masing lokasi penelitian, aktifitasnya

sebagai bahan gambaran umum karyawan pada Guru Yayasan Bhinneka Karya Boyolali.

Bentuk kuesioner berupa daftar pertanyaan yang disampaikan kepada guru yang bekerja di Yayasan Bhinneka Karya Boyolali. Penelitian ini merupakan jenis penelitian survey dengan menggunakan instrument penelitian berupa kuesioner atau angket yang disebarkan kepada responden. Menurut Arikunto (2001:109) yang dimaksud daftar pertanyaan atau angket adalah sejumlah pertanyaan tertulis yang digunakan untuk memperoleh informasi dari responden dalam arti laporan tentang pribadinya atau halhal yang ia ketahui.

Penerapan penelitian ini adalah mengkorelasi variabel bebas yaitu kepemimpinan (X1), lingkungan kerja (X2) dan variabel intervening kepuasan kerja (X3), dengan variabel terikat (Y). Analiisis regresi linier berganda untuk menganaliisa pengaruh variabel bebas independen variabel $(\mathrm{X})$ dan variabel tidak bebas dependen variabel $(\mathrm{Y})$ dengan persamaan :

Persamaan I : $Y_{1}=0,347 X_{1}+0,557 X_{2}+\epsilon_{1}$

Persamaan II : $Y_{2}=0,468 X_{1}+0,325 X_{2}-0,120 X_{3}+$ $\epsilon_{2}$

Tabel 1

Hasil Analisis Jalur Persamaan 1

\begin{tabular}{|c|c|c|c|c|c|c|}
\hline \multicolumn{7}{|c|}{ Coefficientsి } \\
\hline \multirow[b]{2}{*}{ Model } & & \multicolumn{2}{|c|}{$\begin{array}{l}\text { Unstandardized } \\
\text { Coefficients }\end{array}$} & \multirow{2}{*}{\begin{tabular}{|c}
$\begin{array}{c}\text { Standardized } \\
\text { Coefficients }\end{array}$ \\
Beta \\
\end{tabular}} & \multirow[b]{2}{*}{$\mathrm{t}$} & \multirow[b]{2}{*}{ Sig. } \\
\hline & & B & Std. Error & & & \\
\hline 1 & (Constant) & $-3,492$ & 1,739 & & $-2,008$ & , 047 \\
\hline & Kepemimpinan & 406 &, 114 &, 347 & 3,562 & ,001 \\
\hline & Lingkungan Kerj] & ,665 & ,116 &, 557 & 5,726 & ,000 \\
\hline
\end{tabular}

Tabel 2

Hasil Analisis Jalur Persamaan 2

\begin{tabular}{|c|c|c|c|c|c|c|}
\hline \multicolumn{7}{|c|}{ Coefficients } \\
\hline \multirow[b]{2}{*}{ Mode } & & \multicolumn{2}{|c|}{$\begin{array}{l}\text { Unstandardized } \\
\text { Coefficients }\end{array}$} & \multirow{2}{*}{$\begin{array}{c}\text { Standardized } \\
\text { Coefficients } \\
\text { Beta }\end{array}$} & \multirow[b]{2}{*}{$t$} & \multirow[b]{2}{*}{ Sig. } \\
\hline & & B & Std. Error & & & \\
\hline 1 & (Constant) & 4,950 & 1,468 & & 3,372 &, 001 \\
\hline & Kepemimpinan &, 449 & , 100 & ,468 & 4,483 & ,000 \\
\hline & Lingkungan Kerja & ,318 & 111 & ,325 & 2,860 & ,005 \\
\hline & Kepuasan Kerja &, 099 &, 084 & 120 & 1,174 & 243 \\
\hline
\end{tabular}


Tabel 3 Hasil Uji F

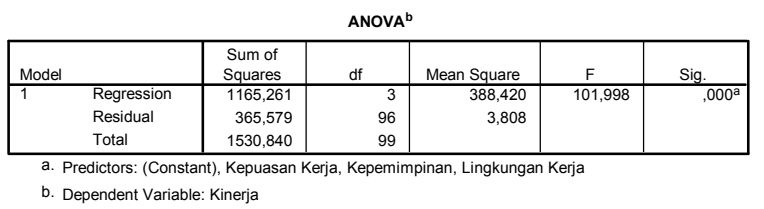

Koefisien determinasi $\left(\mathrm{R}^{2}\right)$ total pengaruh diperoleh nilai koefisien determinasi sebagai berikut:

$$
\begin{aligned}
& \mathrm{R}^{2} \text { total }=1-\left\{\left(\epsilon_{1}\right)^{2} x\left(\epsilon_{2}\right)^{2}\right\} \\
&=1-\left\{(0,486)^{2} \times(0,357)^{2}\right\} \\
&=1-\{(0,236) \times(0,127)\} \\
&=1-0,0299 \\
&=0,970
\end{aligned}
$$

Besarnya Nilai $\mathrm{R}^{2}$ total sebesar 0,970 artinya variasi kinerja karyawan pada Guru Yayasan Bhinneka Karya Boyolali dijelaskan oleh variabel kepemimpinan, lingkungan kerja dan kepuasan kerja, sebesar $97,0 \%$ dan sisanya $3,0 \%$ dijelaskan variabel lain diluar model penelitian sebagai

\begin{tabular}{|c|c|c|c|c|c|}
\hline \multicolumn{6}{|c|}{ Correlations } \\
\hline & & $\begin{array}{c}\text { Kepemim } \\
\text { pinan }\end{array}$ & $\begin{array}{l}\text { Lingkungan } \\
\text { Kerja }\end{array}$ & $\begin{array}{c}\text { Kepuasan } \\
\text { Kerja }\end{array}$ & Kinerja \\
\hline \multirow[t]{3}{*}{ Kepemimpinan } & Pearson Correlation & 1 &, $861^{* *}$ &, $826^{* *}$ & $847^{*}$ \\
\hline & Sig. (2-tailed) & & ,000 & ,000 & ,000 \\
\hline & $\mathrm{N}$ & 100 & 100 & 100 & 100 \\
\hline \multirow{3}{*}{ Lingkungan Kerja } & Pearson Correlation &, $861^{* *}$ & 1 &, $856^{* *}$ &, $831^{*}$ \\
\hline & Sig. (2-tailed) & ,000 & & ,000 & ,000 \\
\hline & $\mathrm{N}$ & 100 & 100 & 100 & 100 \\
\hline \multirow[t]{3}{*}{ Kepuasan Kerja } & Pearson Correlation &, $826^{* *}$ &, $856^{* *}$ & 1 &, $785^{*}$ \\
\hline & Sig. (2-tailed) &, 000 & ,000 & & ,000 \\
\hline & $\mathrm{N}$ & 100 & 100 & 100 & 100 \\
\hline \multirow[t]{3}{*}{ Kinerja } & Pearson Correlation &, $847^{* *}$ &, $831^{* *}$ &, $785^{* *}$ & 1 \\
\hline & Sig. (2-tailed) &, 000 &, 000 &, 000 & \\
\hline & $\mathrm{N}$ & 100 & 100 & 100 & 100 \\
\hline
\end{tabular}
contoh keadaan suatu organisasi dan pengalaman karyawan pada Guru Yayasan Bhinneka Karya Boyolali

Tabel V.18 Hasil Analisis Koefisien Korelasi

Dari tabel di atas hubungan antar variabel dapat digambarkan dengan bagan sebagai berikut:

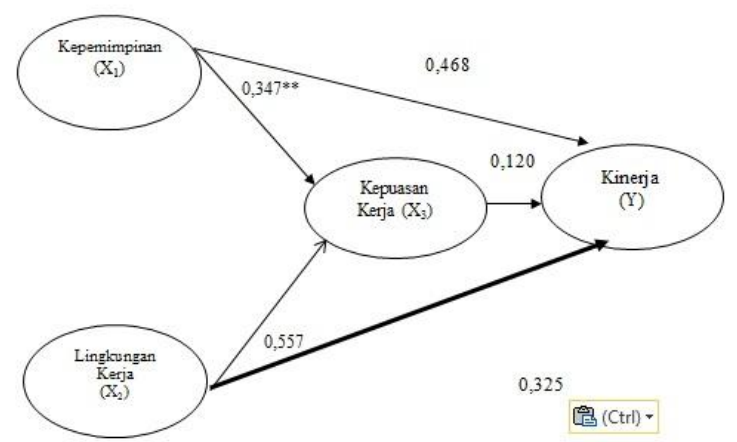

\section{PEMBAHASAN}

\section{Implikasi Manajerial}

1.Pengaruh Kepemimpinan dengan Kinerja melalu kepuasan kerja pada Guru Yayasan Bhinneka Karya Boyolali

Hasil analisis jalur didapat bahwa, pengaruh langsung kepemimpinan berpengaruh signifikan terhadap kinerja karyawan pada Guru Yayasan Bhinneka Karya Boyolali, artinya apabila semakin tinggi kepemimpinan, maka semakin tinggi pula kinerja karyawan pada Guru
Yayasan Bhinneka Karya Boyolali. Hasil penelitian ini mendukung mendukung hasil penelitian yang dilakukan oleh Haryadi Sarjono Lim Sanny, Sheftian Pancha Cahyo (2013), menemukan hasil dalam penelitiannya bahwa kepemimpinan berpengaruh signifikan terhadap kinerja. Hasil penelitian yang dilakukan oleh Karyanto (2014), menemukan hasil dalam penelitiannya bahwa kepemimpinan berpengaruh tidak signifikan terhadap kinerja.

Hasil analisis jalur didapat bahwa, pengaruh tidak langsung diperoleh temuan 
bahwa kepemimpinan berpengaruh signifikan terhadap kepuasan kerja dan kepuasan kerja berpengaruh signifikan terhadap kinerja. Pengaruh lingkungan kerja signifikan terhadap kepuasan kerja. Hasil penelitian ini mendukung hasil penelitian yang dilakukan oleh Karyanto (2014) hasil dalam penelitiannya bahwa kepemimpinan berpengaruh signifikan menemukan terhadap kepuasan kerja. Hasil penelitian ini mendukung hasil penelitian yang dilakukan oleh I Wayan Mudiartha Utama (2012), Rahmila Sari (2011), hasil penelitiannya menunjukkan bahwa kepuasan kerja berpengaruh signifikan terhadap kinerja. Hasil koefisien nilai pengaruh langsung kepemimpinan signifikan terhadap kinerja lebih besar dibandingkan pengaruh tidak langsung, kepemimpinan melalui kepuasan kerja terhadap kinerja maka analisis jalur yang digunakan efektif melalui pengaruh langsung.

Dalam meningkatkan kinerja menggunakan pengaruh langsung yaitu meningkatkan perilaku kepemimpinan sebagai peningkatan perilaku kinerja. Dengan melihat skor uji validitas kepemimpinan pada item pertanyaan nomer 3, 6 dan 4, untuk meningkatkan perilaku kepemimpinan kinerja secara nyata dapat dilihat dari :

a.komunikasi antara pimpinan dan bawahan sudah terjalin dengan baik.

b.Karyawan selalu diperhatikan oleh pimpinan dalam peningkatan prestasi kerja yang dicapai.

c.Karyawan selalu diperhatikan oleh pimpinan dalam peningkatan prestasi

Pengaruh Lingkungan kerja dengan Kinerja melalui kepuasan kerja. Berdasarkan analisis jalur bahwa jalur diketahui pengaruh lingkungan kerja terhadap kinerja signifikan, artinya semakin tinggi tingkat lingkungan kerja, semakin tinggi kinerja yang dihasilkan oleh karyawan pada Guru Yayasan Bhinneka Karya Boyolali. Temuan ini mendukung hasil penelitian yang dilakukan oleh I Wayan Mudiartha Utama (2012), dalam penelitiannya menemukan bahwa lingkungan kerja berpengaruh signifikan terhadap kinerja.

Hasil analisis jalur didapat bahwa, Pengaruh tidak langsung diperoleh dari temuan bahwa lingkungan kerja berpengaruh signifikan terhadap kepuasan kerja dan kepuasan kerja berpengaruh signifikan terhadap kinerja. Untuk meningkatkan perilaku lingkungan kerja maka perilaku kinerja secara kongkrit dilakukan dengan melihat skor uji validitas lingkungan kerja terletak pada item pertanyaan nomer 7,1 dan 4 yaitu: a. Terdapat fasilitas yang mendukung dan memadai sehingga karyawan dapat bekerja secara optimal dengan mengembangkan ide yang kreatif.

b. Karyawan bisa bekerja dengan nyaman jika ruang kerja yang mendukung dengan adanya sirkulasi udara baik.

c.Terdapat hubungan yang baik antara pimpinan dan karyawan di tempat kerja.

Perilaku kinerja karyawan pada Guru Yayasan Bhinneka Karya Boyolali sesuai dengan skor tertinggi dalam uji validitas Kinerja terletak pada butir pertanyaan 3, 4 dan 1 skor tertinggi menandakan bahwa butir tersebut adalah indikator yang dominan membentuk respon terhadap Kinerja, yaitu adanya peningkatan perilaku:

a.Karyawan berusaha bekerja dengan belajar cara kepemimpinan yang diarahkan oleh pimpinan.

b.Karyawan selalu bertanggung jawab terhadap pekerjaan yang dibebankan.

c.Karyawan memiliki prestasi kerja yang cukup baik, demi perkembangan organisasi.

\section{PENUTUP}

\section{Kesimpulan}

1. Hasil dari Uji hipotesa

a. Kepemimpinan berpengaruh positif dan signifikan terhadap kepuasan kerja karyawan pada Guru Yayasan Bhinneka Karya Boyolali.

b. Lingkungan kerja berpengaruh positif dan signifikan terhadap kepuasan kerja karyawan pada Guru Yayasan Bhinneka Karya Boyolali.

c. Kepemimpinan berpengaruh positif dan signifikan terhadap kinerja karyawan pada Guru Yayasan Bhinneka karya Boyolali.

d. Lingkungan kerja berpengaruh positif dan signifikan terhadap kinerja karyawan pada Guru Yayasan Bhinneka Karya Boyolali

e. Kepuasan kerja berpengaruh tidak signifikan terhadap kinerja karyawan pada Guru Yayasan Bhinneka Karya Boyolali

2. Hasil dari uji $F$ diketahui besarnya $F=$ 101,998 signifikansi $0,000<0.005$. Sehingga dapat disimpulkan secara bersama-sama kepemimpinan, lingkungan kerja dan kepuasan kerjaberpengaruh signifikan terhadap kinerja karyawan pada Guru Yayasan Bhinneka Karya Boyolali.

3. Hasil Nilai $R^{2}$ total sebesar 0,970 dapat diartikan variasi kinerja karyawan pada Guru Yayasan Bhinneka Karya Boyolali dijelaskan oleh variabel kepemimpinan, lingkungan kerja dan kepuasan kerja sebesar 97,0 \% dan sisanya $3,0 \%$. 
4. Hasil analisis jalur kepemimpinan terhadap kinerja, merupakan jalur yang efektif untuk meningkatkan kinerja

\section{Saran}

Berdasarkan hasil penelitian dan uraian kesimpulan diatas, maka disarankan hal-hal sebagai berikut :

1. Kepemimpinan merupakan variabel yang paling efektif dalam peningkatan kinerja dilakukan dengan langkah-langkah sebagai berikut:

a.Komunikasi yang baik antara pimpinan dan bawahan dengan menjalin hubungan yang baik.

b.pimpinan lebih memperhatikan karyawan pada Guru Yayasan Bhinneka Karya Boyolali dalam hal prestasi kerja yang dicapai karyawan pada Guru Yayasan Bhinneka Karya Boyolali.

c.Memberikan perhatian khusus terhadap karyawan pada Guru Yayasan Bhinneka Karya Boyolali yang mempunyai prestasi kerja.

2. Lingkungan kerja dalam meningkatkan kinerja dengan cara :

a.Karyawan berusaha bekerja dengan belajar cara kepemimpinan yang diarahkan oleh pimpinan.

b.Karyawan selalu bertanggung jawab terhadap pekerjaan yang dibebankan.

c.Karyawan memiliki prestasi kerja yang cukup baik, demi perkembangan organisasi

\section{UCAPAN TERIMAKASIH}

Penelitian ini merupakan salah satu bagian dari penelitian Hibah Penelitian Ristek Dikti dengan judul terkait yang dibiayai oleh Dikti pada tahun 2017, dan kami mengucapkan rasa terimakasih yang mendalam atas bantuan dana penelitian tersebut.

\section{DAFTAR PUSTAKA}

Agung Widhi Kurniawan , 2012. Pengaruh kepemimpinan dan pengembangan sumber daya manusia terhadap kepuasan kerja, budaya organisasi, dan kinerja karyawan Bank Sulselbar. Jurnal Ekonomi dan Keuangan. Akreditasi No. 80/DIKTI/Kep/2012

Arikunto Suharsimi. 2010. Manajemen Penelitian. Jakarta : Rineka Cipta

Northouse, P. G. (2007). Leadership, theory \& practice. New York: Sage Publishers
Armstrong, Michael, 2008, Hand Book of Personnel Management Practice, Kopan Page Ltd, London

As'ad, Moh. 2011. Psikologi Industri.

Yogyakarta : Liberti

Atmosoeprapto, K, 2010, Produktivitas Aktualisasi Budaya Perusahaan : Mewujudkan Organisasi yang Efektif dan Efisien Melalui SDM Berdaya. Elex Media Komputindo. Jakarta BPFE

FX. Supriyono, 2013. Kepemimpinan, Komunikasi Dan Motivasi Dalam meningkatkan Budaya Organisasi karyawan PT.Makmur Sukoharjo. Jurnal Kepemimpinan FX.Supriyono Vol. 2, 2013

Ghozali, Imam, 2008, Analisis Multivariat, Badan penerbit Undip, Semarang

Gujarati, Damodar. 2005. Ekonometrika Dasar. Erlangga. Jakarta

Handoko, T. Hani. 2006. Manajemen personalia dan sumberdaya manusia. Yogyakarta:

Kreitner, Robeth, Kinnichi, Angelo, 2005, PerilakuOrganisasi, $\quad$ Edisi 5, SalembaEmpat, Jakarta

Kuncoro, Mudrajad, 2011, metode Kuantitatif : Teori dan Aplikasi untuk Bisnis dan Ekonomi, Edisi I, AMP YKPN, Yogyakarta

Made Septiadi, W. G. Supartha. 2012. Pengaruh Kepemimpinan, Komunikasi, Dan Lingkungan Kerja Fisik Terhadap Kepuasan Kerja Karyawan Pada PT.BPR Sriartha Lestari Denpasar. Jurnal Fakultas Ekonomi Universitas Udayana

Mahendra Ahza Putra, 2012, Pengaruh kepemimpinan, pengalaman, lingkungan kerja dan komunikasi terhadap kinerja melalui kepuasan kerja pada Kantor Pemda Kendal. Jurnal Manajemen, Unisbank Semarang. Vol 9.Hal 67-78.

Mangkunegara, Anwar Prabu. 2005. Manajemen Sumber Daya Manusia. Bandung: Remaja Rosda Karya

Mathis, Robert L. Jackson, John H. (peng. bers.);Sadeli, Jimmy (penterj.);Hie, Bayu Prawira (penterj. bers.). 2011. Manajemen sumber daya manusia buku I. Jakarta:Salemba Empat

Neny Ambar Asmarani (2014), Pengaruh Komunikasi Dan Kepemimpinan Terhadap Kinerja Pegawai Melalui Motivasi dan Kepuasan kerja Pada Sekolah Dasar Negeri Wilayah Kecamatan Wonogiri. Tesis Program Magister STIE-AUB Surakarta

Peraturan Pemerintah Republik Indonesia Nomor 46 Tahun 2011. Tentang Penilaian Prestasi Kerja Pegawai Negeri Sipil. 
Pirzada Sami Ullah Sabri, Muhammad Ilyas, Zahra Amjad , 2011. Organizational Culture and Its Impact on the Job Satisfaction of the University Teachers of Lahore. International Journal of Business and Social Science

Robbins Stephen P, Coulter M, 2008 : Management. 8 edition. Pearson Prentice Hall;

Robbins, Stephen, 2014, Perilaku Organisasi. Alih Bahasa Hadyana Pujaatmaka dan Benyamin Molan. Penerbit Prenhallindo. Jakarta. 